\title{
Self-perceived competency of the medical faculty for E-Teaching during the COVID-19 pandemic
}

\author{
Shaur Sarfaraz ${ }^{\mathrm{a}}$, Naseer Ahmed ${ }^{\mathrm{b}, \mathrm{c}}$, Maria S. Abbasi ${ }^{\mathrm{d}}$, Batool Sajjad ${ }^{\mathrm{e}}$, Fahim Vohra ${ }^{\mathrm{f}}$, \\ Rana S. Al-Hamdan ${ }^{\mathrm{g}}$, Ahmed A. Maawadh ${ }^{\mathrm{g}}$, Nawwaf Al-Hamoudi ${ }^{\text {h }}$, Sameer A. Mokeem ${ }^{\mathrm{h}}$, \\ Nada Aldahiyan ${ }^{\mathrm{g}}$ and Tariq Abduljabbar ${ }^{\mathrm{f}, *}$ \\ ${ }^{a}$ Department of Medical Education, Jinnah Sindh Medical University, Karachi, Pakistan \\ ${ }^{\mathrm{b}}$ Department of Prosthodontics, Altamash Institute of Dental Medicine, Karachi, Pakistan \\ c Prosthodontics Unit, School of Dental Sciences, Health Campus, University Sains Malaysia, \\ Kubang Kerian, Kelantan, Malaysia \\ ${ }^{\mathrm{d}}$ Department of Prosthodontics, Altamash Institute of Dental Medicine, Karachi, Pakistan \\ ${ }^{\mathrm{e}}$ Department of Oral Surgery, Altamash Institute of Dental Medicine, Karachi, Pakistan \\ ${ }^{\mathrm{f}}$ Department of Prosthetic Dental Science, College of Dentistry, King Saud University, Riyadh, Saudi Arabia \\ ${ }^{\mathrm{g}}$ Department of Restorative Dental Science, College of Dentistry, King Saud University, Riyadh, Saudi Arabia \\ ${ }^{\mathrm{h}}$ Department of Periodontics and Community Dentistry, College of Dentistry, King Saud University, \\ Riyadh, Saudi Arabia
}

Received 6 August 2020

Accepted 7 September 2020

\begin{abstract}
.
BACKGROUND: The aim of this study was to evaluate the self-perceived competency (FSPC) of medical faculty in E-Teaching and support received during the COVID-19 pandemic.

METHODS: An online well-structured and validated faculty self-perceived competency questionnaire was used to collect responses from medical faculty. The questionnaire consisted of four purposely build sections on competence in student engagement, instructional strategy, technical communication and time management. The responses were recorded using a Likert ordinal scale (1-9). The Questionnaire was uploaded at www.surveys.google.com and the link was distributed through social media outlets and e-mails. Descriptive statistics and Independent paired $t$-test were used for analysis and comparison of quantitative and qualitative variables. A $p$-value of $\leq 0.05$ was considered statistically significant.

RESULTS: A total of 738 responses were assessed. Nearly $54 \%$ (397) participants had less than 5 years of teaching experience, $24.7 \%$ (182) had 6-10 years and $11.7 \%$ (86) had 11-15 years teaching expertise. $75.6 \%$ (558) respondents have delivered online lectures during the pandemic. Asynchronous methods were used by $61 \%$ (450) and synchronous by $39 \%$ (288) of participants. Moreover, 22.4\% (165) participants revealed that their online lectures were evaluated by a structured feedback from experts, while $38.3 \%$ participants chose that their lectures were not evaluated. A significant difference $(p<0.01)$ was found between FSPC scores and online teaching evaluation by experts. The mean score of FSPC scale was 5.62 \pm 1.15 . The mean score for student's engagement, instructional strategies, technical communication and time management were of $5.18 \pm 1.60,5.67 \pm 1.61,5.49 \pm 1.71$ and $6.12 \pm 1.67$ respectively.

CONCLUSION: Medical faculty members were found somewhat competent in E-teaching for student engagement, instructional strategy, technical communication and time management skills. Faculty receiving feedback was more competent in comparison to peers teaching without feedback.
\end{abstract}

Keywords: Teaching staff, competency, SARS-CoV 2 virus, online teaching, health sciences

*Address for correspondence: Tariq Abduljabbar, DMSc, Professor, Department of Prosthetic Dental Science, College of Den- tistry, King Saud University, Riyadh 11545, Saudi Arabia. Tel.: +0096614344777; E-mail: tajabbar@ksu.edu.sa. 


\section{Introduction}

The SARS-CoV-2 virus has grassed up on the world and all sectors of life and divisions have been affected by the Corona virus disease-2019 (COVID19) pandemic. The education sector has not been invisible by its influence and has been trying to evolve itself in the light of this calamity [1]. Governments are struggling to contain the vicious spread of COVID-19 and over a third of the world's population is currently under some form of lockdown [2]. One of the many affected sectors is education [3]. The universities and medical schools had suspended face-to-face teaching, limiting students to move to online distance learning for the indefinite future [4]. A transformative change in the current approach to medical education across the world is inevitable and although the full extent is unknown at present, it is essential to consider potential future scenarios to begin the process of preparing for the future [5].

Online learning (E-Learning) management systems have the capacity to influence university education in many ways. The systems can affect the nature of learning resources, communication between students and staff, the pragmatics of learning, and students' overall interaction with their institution [5]. E learning challenges the faculty to tap into their creative side, as veracity is required to keep the students engaged and interested in the session. They will have to use various online tools and resources, and this will provoke their creative thinking process. While some faculty remain suspicious of the quality of online courses, others have embraced online media as an outlet to increase students' critical thinking, problem-solving and collaborative skills [6]. Medical schools and other medical education providers, including commercial organizations and professional bodies, have rapidly scaled up the provision of educational content and training online, as well as faculty development in the use of technology, especially by online courses. Large group in-person lectures have been replaced by streamed online lectures, using technologies for screen capture and online dissemination. Small group sessions and tutorials have been replaced with interactive Webinars using web conferencing platforms. These learning resources are easily accessible through online gadgets [6, 7].

An effective teaching method engages and strengthens the students to strive for their best. The online instructors must actively participate in the courses or risk the perception of being invisible or absent [8]. Faculty is encouraged to utilize several of the online platform organizational features available, including document sharing, additional lectures, course announcements, discussion threads, and/or webliography to enhance the course delivery and online learning experience. Even though the course content is developed separately, it is the responsibility of the instructor to create an open and inviting climate for communication. The instructor must set the tone for interactions via course tools such as the instructor's office discussion thread, course introductions, and grade book comments [9]. Therefore it is critical to evaluate the competency of teachers of medicine for online teaching.

An obvious paradigm shift has taken place towards digital learning and medical faculty now requires training and working understanding of teaching tools. It is critical for the faculty to understand the need to fundamentally change and transform their pedagogical approaches to the learning and teaching process, to meet the instructional needs of online students [10]. Extensive research has been done on online teaching in the past $[4,6,8]$, however data related to student engagement, instructors strategy, technical communication and time management competency of medical faculty is limited. It is hypothesized, that the faculty will show acceptable self-perceived competency (FSPC) in E-teaching during the Pandemic. Therefore the aim of the present study was to evaluate the Medical faculty self-perceived competency in online teaching and support received during the COVID-19 pandemic.

\section{Material and methods}

\subsection{Study setting and sample}

This descriptive analytical study was conducted from May 4 to June 5, 2020 during the lockdown of COVID-19 pandemic. The institutional Ethics and Review Committee of AIDM approved the study and procedures of informed consent. The sample size was calculated with means and standard deviations from previous studies and a maximum of 1000 medical faculty participants were approached to record their responses to the E-teaching competency questionnaire $[12,13]$. A well-structured questionnaire was formulated as a result of discussion with senior faculty members. The Cronbach's alpha statistical analysis was used to assess the internal consistency (Reliability) of the questionnaire items and a 
strong correlation value of $(\alpha=0.73)$ was recorded. Moreover, face and content validity were carried out by a group of researchers for accuracy of the questionnaire (SS, NA and BS).

\subsection{Questionnaire and data collection}

An online questionnaire was used as a study tool that consisted of 26 closed ended questions. The structured questionnaire consisted of two sections. Section one contained seven questions to collect demographic and professional information included age, gender, experience of teaching in higher education, number of online lectures, current educational level, primary online method of teaching and expert evaluation of online lectures. Section two consisted of 19 items developed after modification from questionnaires proposed by Akaslan, Martin and Vilkas [10-12]. Section two comprised of four subscales that had 4 items from competence in student engagement, 3 from instructional strategies, 6 items from competence in technical communication and 5 from time management. One separate item regarding means of support used by faculty for preparation to teach online during pandemic was also included in the second section. The responses were submitted using a 1-9 Likert ordinal scale with five descriptors above the numbers. The five descriptors were "not at all, very little, somewhat, quite a bit," and "a great deal" approximated to an interval scale as described in (Table 2). The minimum mean score was 1 (minimum score 18 divide by number of items 18) and maximum mean score 9 (maximum scores 162 divided by number of items 18). Lastly the means of the subscales were added to find out an overall faculty's self-perceived competency score. The mean score $(1-<3)$ represented not at all competent, $(\geq 3-<5)$ less competent, $(\geq 5-<7)$ somewhat competent and ( $\geq 7-9)$ as very competent.

Additionally, the questionnaire consisted of brief introduction to study, objective, procedures, voluntarily participation, freedom to withdraw, confidentiality of the subjects and data of research. The questionnaire was uploaded at www.surveys.google.com and the link was distributed through e-mail (Yahoo, outlook, Gmail, Hotmail) and shared on social media (Facebook, Instagram, WhatsApp, LinkedIn, Twitter) with teaching faculty who are shifted from face to face teaching to an online teaching system. The participants with an age 25 years or above were included in the study.

\subsection{Statistical analysis}

The data analysis was performed using statistical program for social sciences (SPSS, 25.0). Descriptive statistics was carried out to obtain the mean, standard deviation, frequency and percentages of quantitative, and qualitative variables. The Independent $t$-test and Paired $t$-test was used to analyze self-perceived competency individually and overall scores for gender disparities and comparison with expert level analysis. With a $95 \%$ confidence interval (CI) the level of significance was set at $p \leq 0.05$.

\section{Results}

Eight hundred and ten questionnaires from participants through an online submission link were submitted. Seventy-two responses were excluded on the basis of repetition. The total number of completed responses was 738 at a response rate of $91.11 \%$. The study included 467 (57.65\%) females and 271 $(36.72 \%)$ males. The mean age of participants was $34.5 \pm 1.56$ years. As far as education level is concerned, $348(47.2 \%)$ participants were postgraduate degree holders and 67 (9.1\%) Doctorate (PhD) holders, while $323(43.8 \%)$ were graduates. In this study the majority $(53.8 \%, \mathrm{n} 397)$ of participants had less

Table 1

Characteristics among study participants $(n=738)$

\begin{tabular}{|c|c|c|}
\hline & Frequency & Percentage \\
\hline \multicolumn{3}{|l|}{ Gender } \\
\hline Male & 271 & 36.7 \\
\hline Female & 467 & 63.6 \\
\hline \multicolumn{3}{|l|}{ Teaching experience } \\
\hline Less than 5 years & 397 & 53.8 \\
\hline $6-10$ years & 182 & 24.7 \\
\hline $11-15$ years & 86 & 11.7 \\
\hline More than 16 years & 73 & 9.9 \\
\hline \multicolumn{3}{|l|}{ No. of lectures delivered } \\
\hline Less than 5 & 291 & 39.4 \\
\hline 6 to 10 & 267 & 36.2 \\
\hline 11 to 15 & 95 & 12.9 \\
\hline More than 16 & 85 & 11.5 \\
\hline \multicolumn{3}{|l|}{ Education level } \\
\hline Graduation & 323 & 43.8 \\
\hline Post-graduation & 348 & 47.2 \\
\hline $\mathrm{PhD}$ & 67 & 9.1 \\
\hline \multicolumn{3}{|l|}{ Online teaching method } \\
\hline Asynchronous & 450 & 61 \\
\hline Synchronous & 288 & 39 \\
\hline \multicolumn{3}{|l|}{ Lecture evaluation } \\
\hline Not at all & 283 & 38.3 \\
\hline Yes, with structured feedback & 165 & 22.4 \\
\hline Yes, with unstructured feedback & 117 & 15.9 \\
\hline Don't know & 173 & 23.4 \\
\hline
\end{tabular}


Table 2

Distribution of scores in different sections of faculty self-perceived competency on a scale $(n=738)$

\begin{tabular}{|c|c|c|c|c|c|c|c|c|c|c|}
\hline \multirow[t]{3}{*}{ Acronym with s. no. } & \multirow{3}{*}{$\begin{array}{l}\text { Item } \\
\text { Student engagement }\end{array}$} & \multicolumn{9}{|c|}{ Likert scale } \\
\hline & & \multicolumn{2}{|c|}{ Not at all $n$} & \multicolumn{2}{|c|}{ Very little $n$} & \multicolumn{2}{|c|}{ Somewhat $n$} & \multicolumn{2}{|c|}{ Quite a bit $n$} & \multirow{2}{*}{$\frac{\text { A great deal } n}{9}$} \\
\hline & & 1 & 2 & 3 & 4 & 5 & 6 & 7 & 8 & \\
\hline SE-1 & $\begin{array}{l}\text { Help your students think critically in } \\
\text { an online class (brainstorming) }\end{array}$ & 15 & 88 & 57 & 56 & 172 & 164 & 84 & 70 & 32 \\
\hline SE-2 & $\begin{array}{l}\text { Engage passive learners in an online class (passive learners: } \\
\text { who might lurk online but fail to actively } \\
\text { contribute/understate to their own learning }\end{array}$ & 20 & 90 & 66 & 97 & 162 & 79 & 166 & 44 & 14 \\
\hline SE-3 & $\begin{array}{l}\text { Control disruptive behavior (e.g. disrespectful } \\
\text { posting or failure to adhere to outline policies } \\
\text { for posting) in an online session }\end{array}$ & 96 & 50 & 85 & 80 & 72 & 132 & 84 & 88 & 51 \\
\hline SE-4 & $\begin{array}{l}\text { Control students dominating online discussions } \\
\text { to encourage equal participation }\end{array}$ & 14 & 26 & 122 & 80 & 98 & 130 & 131 & 102 & 35 \\
\hline \multicolumn{11}{|l|}{ Instructional strategies } \\
\hline IS1 & Explain or exemplify concepts to prevent confusion for students & 0 & 32 & 42 & 44 & 80 & 121 & 100 & 256 & 63 \\
\hline IS2 & $\begin{array}{l}\text { Use a variety of assessment tools for an online course } \\
\text { (e.g.: Kahoot, Socrative, Google Forms) }\end{array}$ & 140 & 56 & 77 & 56 & 90 & 128 & 67 & 84 & 40 \\
\hline IS3 & $\begin{array}{l}\text { Gauge student comprehension of content taught } \\
\text { (e.g.: Scenarios, quiz, group discussion) }\end{array}$ & 18 & 30 & 70 & 54 & 93 & 169 & 138 & 108 & 56 \\
\hline \multicolumn{11}{|c|}{ Technical communication } \\
\hline $\mathrm{TC} 1$ & Send invites/Announcements / email reminders & 15 & 63 & 0 & 72 & 94 & 117 & 141 & 106 & 130 \\
\hline TC2 & $\begin{array}{l}\text { Share open educational resources (e.g. learning websites, } \\
\text { web resources, games and } \\
\text { simulations on Google Drive/Dropbox) }\end{array}$ & 71 & 49 & 34 & 89 & 91 & 135 & 131 & 62 & 76 \\
\hline TC3 & $\begin{array}{l}\text { Use knowledge of copyright law to provide } \\
\text { resources for online students }\end{array}$ & 68 & 73 & 49 & 128 & 109 & 117 & 104 & 41 & 49 \\
\hline TC4 & $\begin{array}{l}\text { Navigate the technical infrastructure provided, } \\
\text { to successfully create and } \\
\text { deliver/upload an online lecture }\end{array}$ & 48 & 52 & 62 & 64 & 97 & 119 & 102 & 127 & 67 \\
\hline TC5 & $\begin{array}{l}\text { Respond to asynchronous discussions (asynchronous } \\
\text { means not online at the } \\
\text { same time e.g: discussion board) }\end{array}$ & 70 & 42 & 52 & 64 & 159 & 60 & 141 & 109 & 41 \\
\hline TC6 & $\begin{array}{l}\text { Respond in synchronous discussions } \\
\text { (e.g. same time chat rooms/whiteboard/Q\&A) }\end{array}$ & 54 & 57 & 62 & 17 & 77 & 76 & 86 & 122 & 187 \\
\hline \multicolumn{11}{|l|}{ Time management } \\
\hline TM1 & $\begin{array}{l}\text { Deliver the required knowledge for the session } \\
\text { to students in the allotted time }\end{array}$ & 14 & 21 & 32 & 85 & 106 & 51 & 135 & 144 & 150 \\
\hline TM2 & $\begin{array}{l}\text { Manage time in conducting/making online lectures (i.e.: starting } \\
\text { and ending lectures on time/uploading on time) }\end{array}$ & 0 & 70 & 34 & 73 & 84 & 33 & 108 & 134 & 202 \\
\hline TM3 & Follow strict deadlines to encourage submission of assignments & 32 & 10 & 74 & 74 & 64 & 100 & 87 & 119 & 178 \\
\hline TM4 & $\begin{array}{l}\text { Provide constructive feedback (within a week) } \\
\text { after submission of the assignment }\end{array}$ & 100 & 24 & 39 & 46 & 84 & 82 & 108 & 89 & 166 \\
\hline TM5 & Allocate time for training to learn new strategies for online lectures & 60 & 77 & 41 & 47 & 118 & 95 & 121 & 99 & 80 \\
\hline
\end{tabular}

Item: Question, SE: Student engagement, IS: Instructional strategies, TC: Technical communication, TM: Time management, FSPCS: Faculty self-perceived competency score, n: Frequency. 
than 5 years of teaching experience, whereas 182 (24.7\%) had 6-10 years, $86(11.7 \%)$ had $11-15$ years and $73(9.9 \%)$ had more than 16 years of teaching practice. $75.6 \%$ (558) participants had prior experience of delivering online lectures. $61 \%$ (450) opted for asynchronous and 39\% (288) preferred synchronous teaching methods. Moreover, $22.4 \%$ (165) participants revealed that their online lectures were evaluated by structured feedback from experts, while $38.3 \%$ (283) participants delivered lectures without evaluations, as presented in Table 1 . The characteristics of FSPC subscales and distribution of responses from faculty on 1 to 9 Likert scale are shown in Table 2.

The mean score of faculty self-perceived competency scale (FSPCS) was $5.62 \pm 1.15$. In addition, further analysis of different segments from FSPCS revealed mean score for student's engagement (SE), instructional strategies (IS), technical communication (TC) and time management (TM) at $5.18 \pm 1.60$, $5.67 \pm 1.61,5.49 \pm 1.71$ and $6.12 \pm 1.67$ respectively (Fig. 1). The faculty response regarding taking help for preparing the online lectures included peer mentoring (33.5\%), expert advice (18.4\%), videos and handbooks $(20.2 \%)$, web resources or tutorials $(33.6 \%)$, workshops and training $174(23.6 \%)$ and consultation with designers (16.3\%). $20.1 \%$ respondents did not take any support for online teaching (Fig. 2).

The FSPCS score for females was $5.55 \pm 1.19$ and $5.73 \pm 1.06$ in males. A significant difference $(p \leq 0.037)$ was observed between mean FSPC scores on the basis of gender. The mean FSPC score when compared with online teaching assessment revealed scores of $6.11 \pm 0.89,5.51 \pm 0.95$ and $5.41 \pm 1.25$ for "structured feedback", "unstructured feedback"

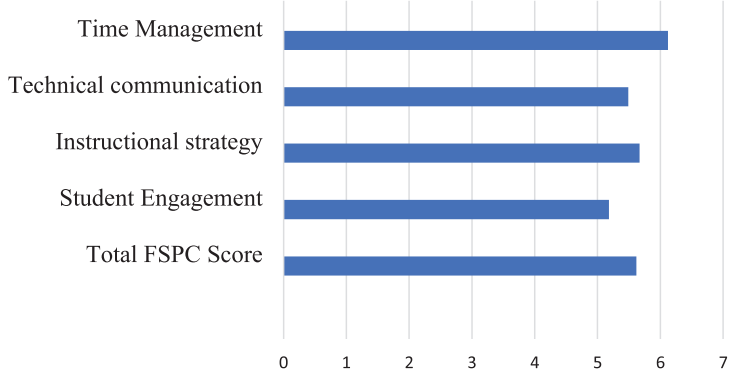

Fig. 1. Distribution of mean subscales and total faculty selfperceived competency scores of online teaching. SE mean score: $5.18 \pm 1.60$, IS mean score: $5.67 \pm 1.61$, TC mean score: $5.49 \pm 1.71$, TM mean score: $6.12 \pm 1.67$, FSPCS: Faculty selfperceived competency score: $5.62 \pm 1.15$.

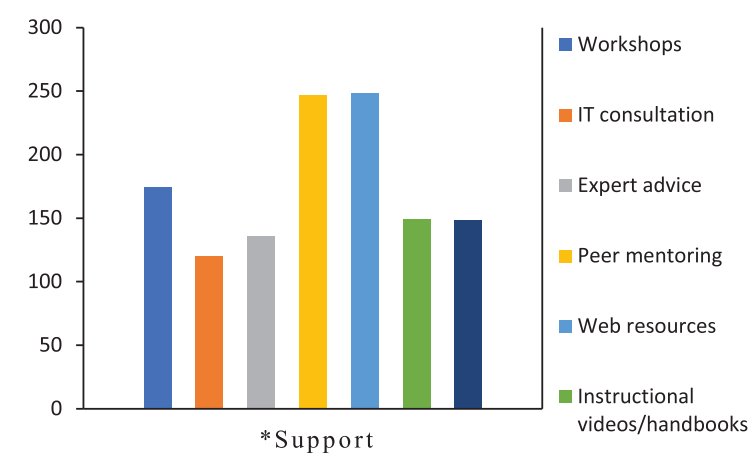

Fig. 2. Distribution of the preferred means of support for online teaching. *Which type of support helped you while preparing to teach online during pandemic, IT: Information Technology.

Table 3

Comparison (mean scores) of expert level evaluation with faculty self-perceived competency

\begin{tabular}{lcccc}
\hline $\begin{array}{l}\text { Lectures evaluated } \\
\text { by experts }\end{array}$ & $\mathrm{N}$ & $\begin{array}{c}\text { FSPC } \\
\text { Score mean }\end{array}$ & $\begin{array}{c}\text { Std. } \\
\text { deviation }\end{array}$ & $P$ value \\
\hline $\begin{array}{l}\text { Not at all } \\
\begin{array}{l}\text { Yes, with structured } \\
\text { feedback }\end{array}\end{array}$ & 283 & 5.41 & 1.25 & 0.001 \\
$\begin{array}{l}\text { Yes, with } \\
\text { unstructured feedback }\end{array}$ & 117 & 5.11 & 0.89 & \\
Do not know & 173 & 5.56 & 1.20 & \\
\hline
\end{tabular}

*FSPCS: Faculty self-perceived competency score, N: Number of responses.

and "not at all" respectively. A significant difference $(p<0.01)$ was found between FSPC scores and online teaching evaluation, as presented in Table 3.

\section{Discussion}

Amidst the current COVID-19 pandemic, a major challenge is to provide and sustain excellence in health care for prevention and treatment of infections. As medical education is critical for health care provision, the importance of electronic teaching (Eteaching, distant learning or online education) could not be emphasized more during this crisis. Therefore, the self-perceived faculty competence working at medical institutes towards online teaching is an important aspect of electronic online schooling [13]. Our study was focused on evaluation of medical faculty competency regarding online teaching using a modified FSPC scale.

Increased age is considered a sign of maturity and learning competencies as described by Eskey et al. [8], however the mean age of participants was $34.5 \pm 1.56$ years in the present study. Moreover, 
47.2\% participants had postgraduate qualifications and $53.8 \%$ had $<5$ years of higher education experience. By contrast, in the study by Mehdinezhad et al., $67.4 \%$ of the faculty had a teaching experience level of 6 to10 years [14]. It is suggested that education level of teachers is associated with improvement in cognitive and psychomotor skills; and self-confidence [15]. Furthermore, $61 \%$ of teachers opted for asynchronous teaching methods while $39 \%$ preferred synchronous teaching instructions. This is in accordance with the findings of the study by Martin et al., where $42.2 \%$ of participants preferred asynchronous while $7.5 \%$ used synchronous means of tutoring [11]. Asynchronous teaching offers ease of access and teaching through e-mails, downloadable materials, recorded tutorials posted on the internet and discussion boards without engaging communication between the student and instructor. On the contrary, synchronous teaching involves exhausting direct interaction and simultaneous participation of all students and teachers in which the audience can communicate with the instructor in real time. The synchronous method was found problematic for students too, due to poor bandwidth and frequent unanticipated interruptions and poor transfer of quality information [16]. Nevertheless, the quality and content of online teaching; needs gradual improvement, which is ideally achieved through strict assessment and feedback [17].

The faculty self-perceived competency in this study was analyzed on the basis of student's engagement skills, instructional strategies, technical communication and time management. The mean score for student's engagement (SE) was $5.18 \pm 1.60$, which revealed that faculty felt somewhat competent in engaging the students during an online class. This score is above average, however improvements in engagement are recommended to enhance the outcomes of E-teaching by medical faculty. Well-implemented learning can expedite knowledge, encourages student's engagement and motivates the learners in the process. According to Saqr et al. and Rios et al. [18, 19], an effective way of learning is encouragement of the students to respond to arguments, discuss concepts, debate viewpoints, and share visions, ideas and alternative perspectives to the discussed topics [13]. Therefore such strategies should be implemented. The mean score for instructional strategies was $5.67 \pm 1.61$. The scale was based on explaining the online lecture content to students, using variety of assessment tools and gauging student comprehension of content taught. The instructional strategies are an important area for the student's success which includes facilitator's active guidance throughout the course along with establishing and adhering to deadlines for assignments, assessment and feedback so that students can improve during the term. Robles and Braathen suggested that "online assessment must be used to measure both learning objectives and application of knowledge" [20].

The mean score for technical communication (TC) was $5.49 \pm 1.71$ in the present study, which exhibited that the faculty felt somewhat competent to communicate via emails for sending invites/ announcements or reminders, sharing educational resources, navigating the technical infrastructure to successfully create, deliver and upload online lectures. While other studies exhibited even better outcomes with scores of $7.44 \pm 0.8452$ [12] and $7.46 \pm 0.733$ [13]. Solis et al. proposed that student learning is associated with the quantity and quality of online discussions [21]. Therefore, a conducive online learning environment should be created that would welcome positive social interaction and active engagement amongst the students and the teachers. In addition, time management for instructors is critical, as it takes longer duration to prepare, plan, and teach an online class [8]. In the present study, time management (TM) scores were promising and the participants excelled in delivering the required knowledge for the session to students in time, managing time in conducting online lecture, following strict deadlines to encourage submission of assignments and providing constructive feedback of the assignments. The results were supported with the studies by Vilkas [12], Dawd [22] and Wolf [16] in which the mean (TM) scores were, $7.36 \pm 0.834$, $4.27 \pm 0.57,6.84 \pm 1.382$ respectively.

The mean FSPC score obtained was $5.62 \pm 1.15$, which demonstrated that the participants feel somewhat competent to teach online. Moreover, the mean FSPCS score when compared with online teaching evaluation revealed that the score for no evaluation at all, evaluation with structured feedback and with unstructured feedback, was $5.41 \pm 1.25,6.11 \pm 0.89$ and $5.51 \pm 0.95$. The level of competency in teaching gets better with experience in both conventional and online form of teaching $[13,23]$. However, other challenges like technology, gadgets and connectivity issues can affect the performance of teaching faculty [22]. Additionally, faculty members who receive more formal online training, seminars, or mentoring programs in a coordinated environment are efficacious and tend to achieve better student outcomes [11]. It is a fact that success of online teaching is 
dependent on supportive and collaborative interaction with student to do brainstorm [8]. However, it is equally important that teachers provide helpful, individualized, constructive feedback on all course assessments to highlight student strengths and provide suggestions for improvement, as applicable [13].

Interestingly, FSPCS scores were better for females than males $(p \leq 0.037)$, which was in accordance with the study by Chang et al. [14], whereas Horvitz et al. [24] revealed no significant difference amongst male and female professors in a range of teaching self-efficacy. Hence, it is difficult to draw a clear conclusion from this finding and further investigations with equal gender participation are needed to concrete the evidence. Moreover, it is essential that institutions recognize that E-teaching is a skill that needs to be developed over time. And quality professional development opportunities for both new and experienced online educators are key to the success of online teaching programs [25]. Our investigation revealed that faculty took help for preparing the online lectures from peer mentoring (33.5\%), resources or tutorials for online teaching (33.6\%) and from professional development workshops (23.6\%), while $20 \%$ of participants navigated online teaching without external assistance. In a study by Dunbar et al., it was recommended that faculty should receive sufficient technical training, pedagogical training, mentoring, and online coursework to avoid malicious gray literature material that lacks scientific basis [13].

Teaching online presents different challenges, therefore higher education institutions around the globe must provide standard and equal training for their faculty members to raise the bar of students' learning during the COVID-19 pandemic. It is pertinent to mention that faculty training; development and ideal conducive online teaching environment initiatives can improve faculty efficiency. Therefore, it is recommended that medical education authorities should adopt a preferred policy for medical faculty to train for online teaching to improve teachers' sense of efficacy during the lockdown. Since integrating these strategies in online teaching, medical faculty can prepare students to learn efficiently, solve complex problems in medical practice and broader health-care system.

\section{Conclusion}

Health science faculty members were found competent in E-teaching for student engagement, instructional strategy, technical communication and time management skills. Faculty receiving feedback was more competent in comparison to peers teaching without feedback. Indicating that instructors need faculty development workshops with structured assessment and feedback to achieve competence to deliver quality lectures and engage students at a satisfactory level required for optimal medical learning.

\section{Acknowledgment}

The authors extend their appreciation to the Deanship of Scientific Research at King Saud University, Riyadh, Saudi Arabia for funding this work through research group No: RG-1438-075.

\section{Authorship contribution}

SS and NA: Conceptualization, methodology, supervision, investigation, software, data curation, writing - original draft.

AM and NA: Data collection, data analyses, data inference.

AM and SM: Questionnaire design, questionnaire validity, data curation, manuscript writing.

BS and MA: Investigation, writing and revision of manuscript, data inference, data assessment.

MA, FV and TAJ: Investigation, questionnaire design and distribution, data curation, writing and revision of manuscript.

\section{Conflict of interest}

The authors declare no conflict of interest.

\section{References}

[1] Franchi T. The Impact of the Covid-19 Pandemic on Current Anatomy Education and Future Careers: A Student's Perspective. Anat Sci Educ. 2020;13:312-5.

[2] Paital B, Das K, Parida SK. Inter nation social lockdown versus medical care against COVID-19, a mild environmental insight with special reference to India. Sci Total Environ. 2020;23:138914.

[3] Viner RM, Russell SJ, Croker H, Packer J, Ward J, Stansfield C, Mytton O, Bonell C, Booy R. School closure and management practices during coronavirus outbreaks including COVID-19: a rapid systematic review. Lancet Child Adoles Health. 2020;4:397-404. 
[4] Kearns LR. Student assessment in online learning: Challenges and effective practices. J Online Lear Teach. 2012;8:198.

[5] Goh PS, Sandars J. A vision of the use of technology in medical education after the COVID-19 pandemic. Med Ed Publish. 2020;26:9.

[6] Trowler V. Student engagement literature review. High Ed Acad. 2010;11:1-15.

[7] Robinia KA. Online Teaching Self-Efficacy of Nurse Faculty Teaching in Public, Accredited Nursing Programs in The State of Michigan. 2008;811. https://scholarworks.wmich.edu/dissertations.

[8] Eskey MT, Schulte M. Comparing attitudes of online instructors and online college students: Quantitative results for training, evaluation and administration. Online J Dist Learn Admin. 2012;15:4.

[9] Keengwe J, Kidd TT. Towards best practices in online learning and teaching in higher education. MERLOT J Online Lea Teach. 2010;6:533-41.

[10] Nisperos LS. Assessing the e-learning readiness of selected Sudanese Universities. Asian J Management Sci \& Edu. 2014;3:45-59.

[11] Martin F, Budhrani K, Wang C. Examining Faculty Perception of Their Readiness to Teach Online. Online Learning. 2019;23:97-119.

[12] Vilkas BJ. A quantitative study of online faculty members' self perceived teaching efficacy. Retrieved from ProQuest Dissertations and Theses. (ED No. 10258632). (2017).

[13] Dunbar M, Melton TD. Self-efficacy and training of faculty who teach Online. In Self-Efficacy in Instructional Technology Contexts. Springer Cham. 2018;15-33.

[14] Mehdinezhad V. Faculty members' understanding of teaching efficacy criteria. Edu Inquiry. 2012;3:49-69.
[15] Chang TS, Lin HH, Song MM. University faculty members' perceptions of their teaching efficacy. Innov Edu Teach Intern. 2011;48:49-60.

[16] Wolf P. Best practices in the training of faculty to teach online. J Comp High Educ. 2006;17:47-78.

[17] Kebritchi M, Lipschuetz A, Santiague L. Issues and challenges for teaching successful online courses in higher education: A literature review. J Educ Tech Sys. 2017;46:429.

[18] Saqr M, Fors U, Tedre M. How the study of online collaborative learning can guide teachers and predict students' performance in a medical course. BMC Med Educ. 2018;18:24. https://doi.org/10.1186/s12909-018-1126-1.

[19] Rios T, Elliott M, Mandernach BJ. Efficient instructional strategies for maximizing online student satisfaction. J Educ Online. 2018;15:n3.

[20] Robles M, Braathen S. Online assessment techniques. Delta Pi Epsilon J. 2002;44:39-49.

[21] Solis OJ, Turner WD. Building positive student-instructor interactions: Engaging students through caring leadership in the classroom. J Empow Teach Excel. 2017;1:4.

[22] Dawd S. The promise of e-platform technology in medical education. Ethio J Health Sci. 2016;26:173-8.

[23] Bawane J, Spector JM. Prioritization of online instructor roles: implications for competency based teacher education programs. Dist Educ. 2009;30:383-97.

[24] Horvitz BS, Beach AL, Anderson ML, Xia J. Examination of Faculty Self-efficacy Related to Online Teaching. Innov High Educ. 2015;4:305-16.

[25] Vaill A, Testori P, Orientation, mentoring and ongoing support: A three-tiered approach to online faculty development. J Asynch Learn Net. 2012;16:111-9. 